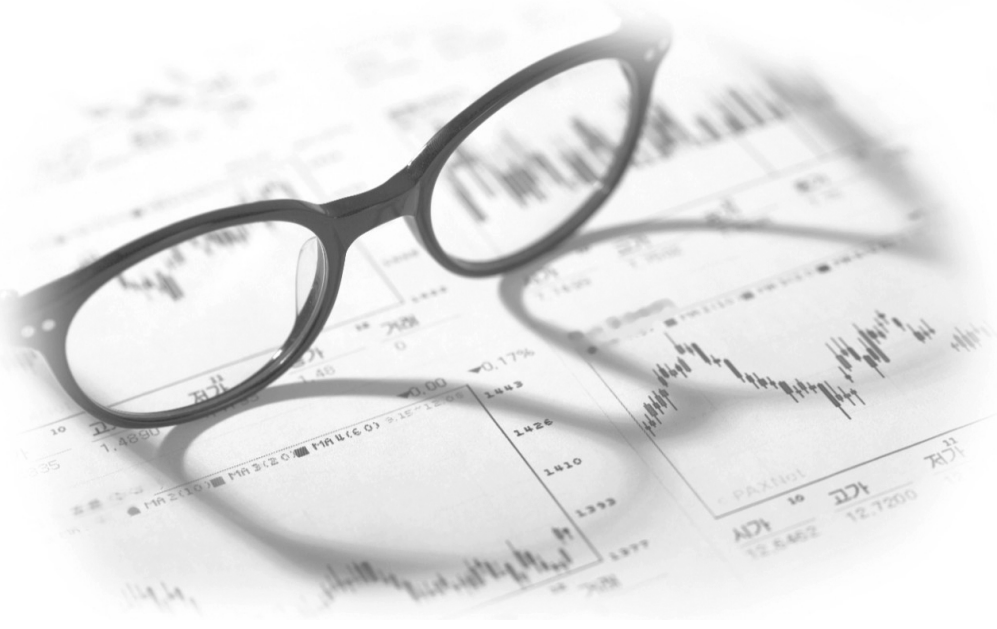

BLOOD RESEARCH

Volume $56 \cdot$ Number $1 \cdot$ March 2021

https://doi.org/10.5045/br.2021.2021021

Perspective

\section{COVID-19 pandemic: a double-edged sword for cord blood banking}

\author{
Young-Ho Lee, M.D., Ph.D. \\ Department of Pediatrics, Hanyang University Medical Center, \\ Hanyang University College of Medicine, Seoul, Korea
}

Received on January 28, 2021; Revised on March 5, 2021;

Accepted on March 11, 2021

\section{INTRODUCTION}

Coronavirus disease 2019 (COVID-19) has affected so many areas worldwide, including the economy, as well as many medical fields. The pandemic has also impacted all aspects of stem cell transplantation (SCT) on the donor, as well as the recipient, side. The Worldwide Network for Blood and Marrow Transplantation (WBMT) and Center for International Blood and Marrow Transplant Research (CIBMTR) have jointly produced an expert opinion statement as a general guide to certain current aspects of SCT [1].

I propose to review the impact of COVID-19 on cord blood (CB) banking. Fear of vertical transmission of coronavirus could decrease CB donation. In addition, in SCT settings, coronavirus infections could increase the morbidity of cord blood transplantation (CBT) recipients, which could decrease the use of banked $\mathrm{CB}$ units. On the other hand, the national marrow donor program (NMDP) recommends having back up CB units for all unrelated SCT from adult donors, in case the selected adult donor becomes unavailable for collection due to COVID-19 infection. For this reason, there was increased use of CB units in the US in March 2020. In addition, several clinical trials have examined the use of CBs and birthing tissues in patients with COVID-19, and clinical trials using $\mathrm{CB}$-based cell therapeutics for COVID-19 could increase the future need for CB banking. I will review several findings concerning these two aspects of the impact of COVID-19.

Impact of vertical transmission of COVID-19 on CB donation and banking

I have tried to compare numbers of recipients and donors for SCT before and after the onset of COVID-19 (Mar. 2020) in Korea. Numbers of unrelated SCTs using bone marrow (BM) or peripheral blood (PB) were similar in 2019 and 2020, and were thus not affected by the COVID-19 pandemic. However, numbers of volunteer adult stem cell donors decreased dramatically for several months after Mar 2020, compared to 2018 and 2019, and then it has been recovered since July 2020. CBT activity did not decline in the COVID-19 era, but the number of donated CBs fell dramatically from Mar 2020 (Fig. 1).

If vertical transmission of COVID-19 is possible, it would be a great barrier to $C B$ donation and would need to be suggested as a new exclusion criteria for $\mathrm{CB}$ donation. As is well-known, SARS-1 was vertically transmitted, while MERS was not [2]. Unfortunately there is limited evidence so far about this for COVID-19. Researchers have suggested several possible scenarios for the vertical transmission of severe acute respiratory distress syndrome coronavirus 2 (SARS-CoV-2, 2019 novel coronavirus). First, angiotensinconverting enzyme 2 (ACE2), a known receptor for SARS$\mathrm{CoV}-2$, is expressed on the trophoblast, especially in the first trimester. Second, SARS-CoV-2 RNA has been found in the placental tissues or membranes of newborns delivered by COVID-19-infected mothers. Third, immunoglobulin (Ig) $\mathrm{M}$ and IgG antibodies against SARS-CoV-2 are elevated 


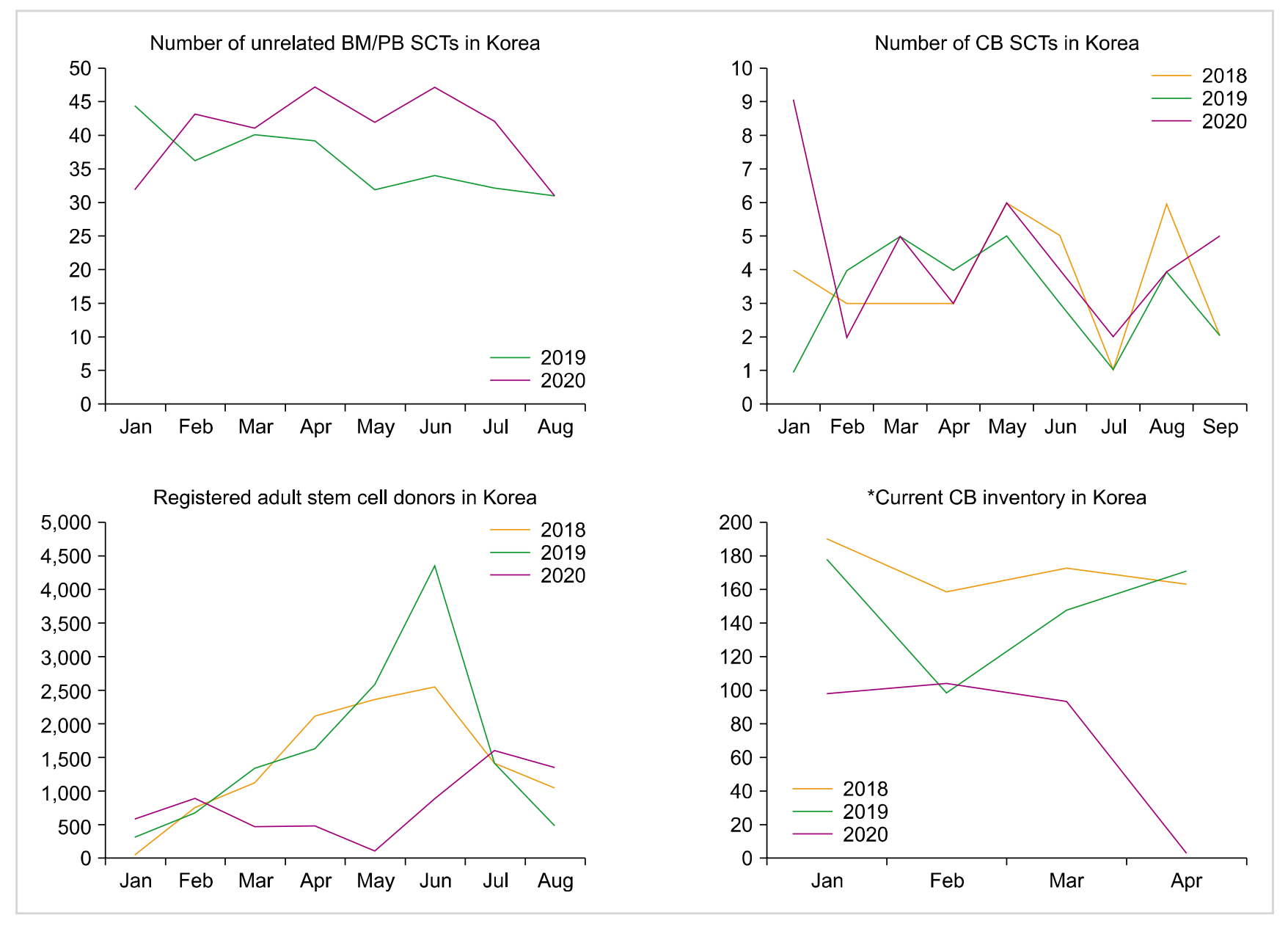

Fig. 1. Numbers of recipients and donors for stem cell transplantation before and after onset of COVID-19 (Mar. 2020) in Korea. *The data of current CB inventory are presented just until April because the donated cord bloods are registered on the national registry by "Cord Blood Act" in Korea, after 6 months of observation period for the health status of neonates. (These data are kindly provided by Korea Marrow Donor Program and Ministry of Health \& Welfare of Korea).

Abbreviations: BM, bone marrow; $\mathrm{CB}$, cord blood; $\mathrm{PB}$, mobilized peripheral blood stem cells; SCT, stem cell transplantation.

in newborns from COVID-19-infected mothers [3].

I have examined two large systematic reviews of the risk of vertical transmission. The first included either mothers with confirmed COVID-19 based on a positive swab, or cases where there was high clinical suspicion of COVID-19 although a swab had not been taken, e.g. symptoms and radiographical evidence in an area of high COVID-19 prevalence [4]. From this article, I assessed the incidence of COVID-19 (+) in neonates of confirmed mothers according to country. The incidence varied from $0 \%$ to $20 \%$, with a mean of $4.6 \%$. Neonatal infection was thus uncommon, and it was almost never symptomatic. In addition, the rate of infection did not increase when the baby was born vaginally, breastfed or allowed contact with the mother. The authors identified several limitations of the studies included in the review. It has been proposed that to definitely establish vertical transmission, the virus should be detected by polymerase chain reaction (PCR) in umbilical cord blood, neonatal blood collected within the first 12 hours of birth or amniotic fluid collected prior to rupture of the membranes. However, many studies simply identified vertical transmission on the basis of positive nasopharyngeal swabs and/or the presence of IgG for COVID-19 in neonates, which could result from contamination and is not diagnostic. The other systematic review found no cases of vertical transmission among 310 deliveries for which reversetranscription polymerase chain reaction data were available [5].

Do the above studies suggest that donor screening for corona virus is necessary for CB banking? The answer is that, so far, donor screening is not necessary because vertical transmission of COVID-19 seems to be rare. However, medical history questionnaire items concerning COVID-19 infection of mothers and their family should be included in assessments to permit banked CBs to be discarded based on future data.

\section{CB-based cell therapy for COVID-19}

Many clinical trials have been performed since the onset of the COVID-19 pandemic. Many drugs have been examined 
in clinical trials, and $10.2 \%$ of registered COVID-19 studies used stem cells and $\mathrm{CB}$ to try to prevent progression of COVID-19. Most of the clinical trials using CB and birthing tissue to treat COVID-19 patients employed with the backgrounds of CBs to suppress hyperinflammatory status. They used the expanded CB-derived cells, umbilical cordderived mesenchymal stem cells (MSCs) or CB-derived regulatory $\mathrm{T}$ (Treg) cells [6].

In an ongoing pilot study, expanded CB-derived cells, are being used at a dose of 5 million cells $/ \mathrm{kg}$ and infused intravenously over 30-60 minutes [7]. In the trial using umbilical cord-derived MSCs (UC-MSCs) 18 patients were enrolled and allogeneic MSCs derived from Wharton's jelly of umbilical cord tissue were infused on days 0,3 , and 6. The total volume of the UC-MSCs infused was $60 \mathrm{~mL}$. There were no serious adverse events associated with infusion; all 18 patients recovered and were discharged, and the time from admission to discharge was the same in the treated group and control group [8]. Another ongoing study is assessing the safety of a single intravenous infusion of UC-MSCs in patients with acute respiratory distress syndrome (ARDS) due to COVID-19. The study uses a fixed dose of $400 \times 10^{6}$ cells in a volume of $40 \mathrm{~mL}$ diluted to 200 $\mathrm{mL}$ in Plasma-Lyte 148 for administration [9].

In another trial of cell therapy, CB-derived Treg cells are being used to treat COVID-19 ARDS patients. Tregs and their functions are compromised in COVID-19 patients, and dysregulated antigen presenting cells (APCs) enhance tissue inflammation and immunopathology by secreting inflammatory cytokines and activating a T-cell-dependent immune response. Either adoptive transfer of allogenic Tregs or use of Treg-derived molecules could in principle block the activation of APCs and costimulatory pathways [10] and arrest tissue inflammation and immunopathology, permitting better management of patients. I recently communicated with Dr. Parmar of the MD Anderson Cancer Center, who is performing this clinical trial. She kindly sent a brief summary of the data from the ongoing trial, according to which 2 cycles of cryopreserved CB Treg cells led to clinical improvement and extubation of the COVID-19 ARDS patients, and dampened the cytokine storm by reducing c-reactive protein, ferritin, aspartate transaminase and interleukin-6 levels. On the other hand, absolute lymphocyte count increased after Treg infusion (personal communication).

\section{CONCLUSIONS}

Fear of the COVID-19 pandemic may discourage CB donation, which could reduce $\mathrm{CB}$ inventories. However, safe practice at collection sites should encourage ongoing donation and collection because there is little documented evidence of vertical transmission. The use of banked CBs and birthing tissues against pandemic viral infections such as COVID-19 would enhance the need for CB banking.

\section{Author's Disclosures of Potential Conflicts of Interest}

No potential conflicts of interest relevant to this article were reported.

\section{REFERENCES}

1. Algwaiz G, Aljurf M, Koh M, et al. Real-world issues and potential solutions in hematopoietic cell transplantation during the COVID-19 pandemic: perspectives from the Worldwide Network for Blood and Marrow Transplantation and Center for International Blood and Marrow Transplant Research Health Services and International Studies Committee. Biol Blood Marrow Transplant 2020;26:2181-9.

2. Diriba K, Awulachew E, Getu E. The effect of coronavirus infection (SARS-CoV-2, MERS-CoV, and SARS-CoV) during pregnancy and the possibility of vertical maternal-fetal transmission: a systematic review and meta-analysis. Eur J Med Res 2020;25:39.

3. Edlow AG, Li JZ, Collier AY, et al. Assessment of maternal and neonatal SARS-CoV-2 viral load, transplacental antibody transfer, and placental pathology in pregnancies during the COVID-19 pandemic. JAMA Netw Open 2020;3:e2030455.

4. Walker KF, O'Donoghue K, Grace N, et al. Maternal transmission of SARS-COV-2 to the neonate, and possible routes for such transmission: a systematic review and critical analysis. BJOG 2020;127:1324-36.

5. Huntley BJF, Huntley ES, Di Mascio D, Chen T, Berghella V, Chauhan SP. Rates of maternal and perinatal mortality and vertical transmission in pregnancies complicated by severe acute respiratory syndrome coronavirus 2 (SARS-Co-V-2) infection: a systematic review. Obstet Gynecol 2020;136:303-12.

6. Yang M, Shang YX, Tian ZY, et al. Characteristics of registered studies for Coronavirus disease 2019 (COVID-19): a systematic review. Integr Med Res 2020;9:100426.

7. Malhotra A, Ernest D, Rogers BA, et al. Umbilical cord blood therapy to prevent progression of COVID-19 related pneumonia: a structured summary of a study protocol for a pilot randomised controlled trial. Trials 2020;21:474.

8. Meng F, Xu R, Wang S, et al. Human umbilical cord-derived mesenchymal stem cell therapy in patients with COVID-19: a phase 1 clinical trial. Signal Transduct Target Ther 2020;5:172.

9. Gorman E, Shankar-Hari M, Hopkins P, et al. Repair of acute respiratory distress syndrome by stromal cell administration in COVID-19 (REALIST-COVID-19): a structured summary of a study protocol for a randomised, controlled trial. Trials 2020; 21:462.

10. Stephen-Victor E, Das M, Karnam A, Pitard B, Gautier JF, Bayry J. Potential of regulatory $\mathrm{T}$-cell based therapies in the management of severe COVID-19. Eur Respir J 2020;56:2002182. 